\title{
Is a methodology available that accurately measures the cost of an FDG-PET study?
}

\author{
Bruno Krug • Anne Sophie Pirson • Ralph Crott • \\ Thierry Vander Borght
}

Received: 24 October 2006 / Accepted: 25 October 2006 / Published online: 8 December 2006

(C) Springer-Verlag 2006

Health care expenses are escalating in many countries. With more restrictive reimbursement schemes based on case-mix funding systems, increasing complexity and rising costs, the health care sector faces a new challenge in becoming more cost efficient. In nuclear medicine, as in other specialties, the rapid growth and development of medical technology has contributed significantly to the steady increase in the costs of medical care. Hospital administrators and governments are being forced to take difficult decisions regarding which new developments in nuclear medicine should be supported financially, e.g. construction of a cyclotron facility, acquisition of new hybrid devices (SPECT/CT and PET/CT) or building of shielded rooms for metabolic therapies $[1,2]$.

Cost-effectiveness is now being used by many payers as a criterion for health care coverage, necessitating estimation of the economic effects of incorporating a technological innovation. Implicit in economic analysis is the assignment of some monetary cost to the considered intervention. Cost measurement is a complex matter, however, and there is a lack of clarity both in the terminology and in the cost concepts utilised. Cost is a term that can have several definitions in medical economics [3].

Especially in fee-for-service health systems, "costs" may refer to charges or to actual direct medical costs. A health care charge is synonymous with the administrative price,

B. Krug $(\bowtie) \cdot$ A. S. Pirson $\cdot$ T. Vander Borght

Nuclear Medicine Department, Université Catholique de Louvain,

1 Dr Thérasse,

5530 Yvoir, Belgium

e-mail: bruno.krug@imre.ucl.ac.be

R. Crott

Belgian Health Care Knowledge Center,

Brussels, Belgium reflecting the amount requested by an institution or office practice for a given admission, procedure or office visit from third party payers or patients. Most health care organisations have a predetermined charge for each type of service, but the charge may not accurately portray the underlying true cost of providing the service because of historical and political factors, regulatory compliance, budget constraints and market forces. Allocating cost based on revenues may become arbitrary when fees are determined independently of costs [1].

Although the importance of accurate cost data in respect of an FDG-PET study has been recognised, most cost estimates have focussed on average cost per procedure extrapolated from a global cost. Because they are easy to obtain, indirect top-down methods are used to estimate the costs: (a) using hospital charges to estimate hospital costs and physician fees to estimate the cost of professional services, (b) averaging multiple hospital and physician charges, (c) adjusting charges by cost-charge ratios and (d) using third party payments as proxies for resource costs. The differences in methods used, cost components included and health care systems make comparisons unreliable [4-6].

In this era of intense cost containment there is an urgent need for more accurate data on the precise costs of a health care procedure. Unfortunately, we currently lack well-accepted metrics for the accurate determination of costs. Current hospital accounting systems do not provide the information needed to determine the cost of a medical service or to make decisions. Traditional accounting systems break down costs into direct and indirect costs. Direct costs comprise expenditure on resources, in the form of specific products (e.g. the price of radiopharmaceuticals or other consumables, the acquisition or repair cost of a PET scanner). Slightly murkier are indirect costs, which are defined by default. These indirect costs 
comprise departmental support activities (financial, general, maintenance and energy costs), hospital support activities (general coordination and administration, personnel accommodation and IT department), non-assigned building costs and different types of medical wage costs (the time dedicated to research, reading professional literature, teaching and clinical activities).

Fundamental problems arise when allocating FDG-PET costs using traditional accounting approaches. First, traditional systems fail to reflect the underlying diversity of work within a hospital environment. Second, they use allocations that are, for the most part, relatively arbitrary. Single-step allocations fail to reflect the real work; in other words, the activities performed and the associated resources actually consumed. Therefore, indirect costs must be directly allocated to the products. Third, they only provide a cost number that, standing alone, does not provide any guidance on how to improve performance by lowering cost or enhancing throughput [7]. The result is a distortion of product costs due to aggregated cost information. In reality, most traditional accounting methods were designed to develop information for external sources (auditors, boards, taxes). They were not meant either to trace factors that give rise to costs or to permit development of prospective health care resource allocation strategies.

In order to assist analysis of cost efficiency, health care organisations may want to adopt more refined costing techniques. One of them is the activity-based costing (ABC) accounting approach. Instead of a traditional volume-based approach, the basic principle of this accounting method is a process-oriented cost analysis by tracing health care activities back to events that generate the cost.

This micro-costing technique relies on a multi-stage process, which traces resources (salaries, rent, equipment, etc.) to the activities associated with use of these resources. The first step is a process analysis, which involves mapping activities in an illustrated sequence. When mapping a health care activity, processes are broken down into a network of activities and sub-activities, and recorded in a flowchart format. This describes the sequence of activities and the various associations or links between activities. In an $\mathrm{ABC}$ accounting method, activities are classified as primary activities (directly related to patient care) or secondary activities (support activities) [7-10]. The weakness of this step concerns the level of detail required. The precision of the $\mathrm{ABC}$ system and the resulting cost calculation depend critically on the level of detail of its components. However, getting down to the desired minute, almost infinite level of detail regarding costs, activities, products and cost drivers is a very labour-intensive process. Performance of detailed cost analyses often entails establishing a consensus in the identification of key activities, which involve the consumption of a large amount of resources, and then "unbundling" these activities. With the focus on the key activities and the integration of the different health care information technology systems (such as patient scheduling, hospital information, purchasing, billing systems, etc.), these concerns are reduced [7, 11].

In a second step, the costs are allocated to these activities and the activities to the products, using respectively resource and activity drivers. Beyond this additional allocation step, another difference between traditional and $\mathrm{ABC}$ accounting approaches is the use of cost drivers. A cost driver is defined as any factor that directly affects the cost of a product or service (e.g. time slots, number of patients, number of operating days, amount of material ordered, paperwork required for monitoring). Traditional approaches use only a few (mostly volume-based) cost drivers (e.g. machine hours of the PET scanner), whereas in the $\mathrm{ABC}$ cost-accounting model, a larger number of diverse cost drivers are used to reflect the relation between the resource costs and the activities as well as between the activities and the products. They are based on volume (e.g. scheduling, billing) or time (e.g. machine time slots, medical clinical time, maintenance, depreciation of equipment and space) or are derived on a per unit basis (e.g. radiopharmaceuticals, consumables).

In the last step, the costs of the different resource categories (wages, materials, equipment and space) are assigned to the different activities and the products. The ABC model attempts to delineate these "aggregated" indirect costs and to assign them more accurately, through cost drivers, to the activities that are consuming the resources [8-10].

One of the difficulties of this micro-costing approach is collection of the information needed to drive the $\mathrm{ABC}$ model. For example, to evaluate the total cost of a PET study in an academic setting, one also needs to estimate the mission-related costs of a teaching hospital. An accurate cost estimate will therefore need, for example, an evaluation of the expenses and hours spent on teaching and research [12].

Not all indirect costs can be assigned accurately to activities or the amount of effort spent on these calculations may not be worth the time commitment (e.g. heating costs or janitorial expenses are allocated using the square feet per department). If the degree of precision has little impact on the total cost or does not significantly enhance management's understanding of operations, gross allocations can still be made.

The construction of any accounting model involves a certain degree of uncertainty and a certain number of assumptions. Some centres may argue that several of the cost components are different in their centre, for a variety of reasons, e.g. international differences in legislation, wage costs or wage structure, or in who performs the procedure 
(nurses versus technicians). Even within the same country, costs may differ substantially despite, for example, application of the same legislation and the same overall wage rates. Therefore it is necessary to investigate the impact of cost components on the overall conclusion by means of a sensitivity analysis. Through a sensitivity analysis, some of the cost components (e.g. the acquisition of a hybrid PET/ CT scanner, the patient throughput and the sales prices for the FDG dose) will be analysed with regard to the assumptions made, so that the sensitivity of critical estimations in varying circumstances is examined [4].

ABC goes beyond being just a more accurate accounting system or a cost management tool. Activity-based management can be used for operational decision making to improve the departmental workflow and to understand the financial impact of changes in consumption patterns or of the acquisition of new equipment, such as purchase of a new hybrid scanner or establishment of a PET-CT facility. With capitated or diagnosis related group based reimbursement systems and the growing use of integrated care pathways, delineating costs at this procedural level has become fundamental $[8,13,14]$.

Economic studies will increasingly guide health care resource allocation decisions in this age of changing financial incentives. Although cost-effectiveness is becoming the foremost evaluative criterion, scientific knowledge about cost patterns is limited. To ascertain the cost side of a cost-benefit equation, we therefore need to ensure that standardised methodologies for the accurate determination of cost estimates receive adequate attention in the foreseeable future. A standardised costing methodology would facilitate comparisons and transferability of results and encourage economic evaluation, and hence assist in the decision-making process with regard to the efficient allocation of resources [3, 15, 16]. Better understanding and standardisation of cost analyses are especially important when promoting expensive imaging modalities, such as PET-CT, in a medical world more and more driven by economic considerations.

In conclusion, among the accounting methods, activitybased costing provides more accurate and meaningful cost information which may be used to better understand and characterise the different cost components and to calculate a cost estimation for an operating PET facility.

\section{References}

1. Blackmore CC, Smith WJ. Economic analyses of radiological procedures: a methodological evaluation of the medical literature. Eur J Radiol 1998;27:123-30.

2. Gambhir SS. Economics of nuclear medicine. Introduction. Q J Nucl Med 2000;44:103-4.

3. Oostenbrink JB, Koopmanschap MA, Rutten FF. Standardisation of costs: the Dutch Manual for Costing in economic evaluations. Pharmacoeconomics 2002;20:443-54.

4. Drummond M, O'Brien B, Stoddart G. Methods for the economic evaluation of health care programs.New York: Oxford University Press;1997.

5. Nisenbaum HL, Birnbaum BA, Myers MM, Grossman RI, Gefter WB, Langlotz CP. The costs of CT procedures in an academic radiology department determined by an activity-based costing (ABC) method. J Comput Assist Tomogr 2000;24:813-23.

6. Chuck A, Jacobs P, Logus JW, St Hilaire D, Chmielowiec C, McEwan AJ. Marginal cost of operating a positron emission tomography center in a regulatory environment. Int $\mathrm{J}$ Technol Assess Health Care 2005;21:442-51.

7. Monge P. The importance of activity-based methods in radiology and the technology that now makes this possible. Radiol Manage 2006;28:52-5.

8. Baker J. Activity-based costing and activity-based management for health care. Gaithersburg, MD: Aspen; 1998.

9. Canby JB 4th. Applying activity-based costing to healthcare settings. Healthc Financ Manage 1995;49:50-52, 54-6.

10. Gabram SG, Mendola RA, Rozenfeld J, Gamelli RL. Why activity-based costing works. Physician Exec 1997;23:31-7.

11. Kaplan RS, Anderson SR. Time-driven activity-based costing. Harv Bus Rev 2004;82:131-8, 150.

12. Cohen MD, Hawes DR, Hutchins GD, McPhee WD, LaMasters MB, Fallon RP. Activity-based cost analysis: a method of analyzing the financial and operating performance of academic radiology departments. Radiology 2000;215:708-16.

13. Player S. Activity-based analyses lead to better decision making. Healthc Financ Manage 1998;52:66-70.

14. Aird B. Activity-based cost management in health care - another fad? Int J Health Care Qual Assur 1996;9:16-9.

15. Adam T, Koopmanschap MA, Evans DB. Cost-effectiveness analysis: can we reduce variability in costing methods? Int $\mathrm{J}$ Technol Assess Health Care 2003;19:407-20.

16. Negrini D, Kettle A, Sheppard L, Mills GH, Edbrooke DL. The cost of a hospital ward in Europe: is there a methodology available to accurately measure the costs? J Health Organ Manag 2004;18:195-206. 